\title{
15. Pictures at Tabara
}

Overland 109 (1987), pp. 6-14.

Along the north bank of the Gira River in the Northern Province of Papua New Guinea the walking track winds through sharp changes of deep shade, half shade and bright sunlight. Even with our eyes full of sweat we were conscious of the condition of the light. Near Nindewari Village, in an open area of shimmering heat, there was a patch of swept earth, white stone border, bright crotons, fenced square, and in the centre a peaked corrugated iron roof supported by stakes. Although not a grave, it looked like a memorial of some sort. We wanted to cross the intense heat of the open space and escape into the dark heat of the rain forest; but we asked what it was.

Many of the young people of the area know a little English, and they speak it with a distinctive, clipped carefulness. Five or six of them answered, each giving a quick rush of words. Perhaps they were translating from their own language, and while one was talking another was choosing the foreign words to push the story along its well-known track:

A young man. He was only fifteen or sixteen. He was making love to a married woman. They used to meet very often. Then the husband found out. He came back to the village in the early afternoon. He sat there sharpening his bush knife. For a long time. In the evening he waited here by the track. When the young man came along he killed him. He kept cutting and cutting. And he threw all the pieces away in the bush. Then he ran. He went to Ioma. He travelled all night. To give himself up to the police. The people gathered all the bits of the body. They found every piece except his cock and balls. They smoked the body to keep it so that the government men could look at it. This (and they indicated the fence, crotons, and roof) is the place where the young man was killed. He is not buried here. He is buried in the village cemetery.

The story was dramatic and grotesque. Such stories are attractive to Australians who have just arrived in Papua New Guinea. The stories confirm what they hoped: they have passed beyond the Australian frontier to the exotic. And they are themselves unthreatened. They cannot wait to write home, or get home and talk about it.

We had flown in from Popondetta to Dodoima on a six-seater Islander, crossing the uniform pattern of oil palms, the mass of rain forest, the Kumusi, Opi and Mambare Rivers, and losing height over curve on curve of the Gira. Dodoima airstrip is a patch of vivid green where the Gira leaves the foothills of the central 
ranges and begins its north-eastward surge to the Solomon Sea. At Dodoima some Binandere saw their first wheeled machinery: on the undercarriage of an aircraft or on the Scott Bonnar mower used to help cut the kiawa (whiteman's) grass on the runway.

Chris Owen, Andrew Pike and I were going to Tabara village with John Waiko. John had recently graduated from The Australian National University in Canberra, the second Papua New Guinean to gain a PhD. Amid flowing robes, floppy hats, mortar boards and speeches, John had stepped forward to take his degree wearing a gown, feathered headdress and shell face ornaments. Now his Binandere people were to celebrate his doctorate. We three foreigners had come to take part, watch and record.

At Popondetta airport the Papuan clerk stated on the loading form that each of us weighed seventy-seven kilos. Was that the known average weight of white travellers in the tropics, or did we all look the same?

It was a four-hour walk from Dodoima to John Waiko's village of Tabara. After three hours the unpracticed walkers among us could not alter stride without feeling pain. We were fixed in mobility.

The track crossed a succession of steep-sided creeks feeding into the Gira. Some were bridged by heavy tree trunks adzed flat on top, and at other longer crossings the logs tapered to sapling, bending and whipping with each stride. All the barefoot Binandere, including those with awkward two-man loads lashed to poles, slapped their feet confidently on wood over space. At each creek we measured our agility and comfort against humility. We could follow the lead of the Binandere; bounce across on our backsides; or ignore the bridge, plunge into dense bush, wade through stagnant water and haul ourselves up the far bank. The Binandere watched closely and covertly. All hoped for a spectacular display of foreign ungainliness so that they would later mime, laugh, mime, and laugh again. We avoided disaster, but at the expense of pride, splinters, scratches and a soaking to the waist.

Less than an hour out of Tabara we were told to board outrigger canoes. Each time a white boot was placed in the main hull, a Binandere politely urged us, 'Watch the outrigger'. I thought this curious advice until I realised that it was the lightwood outrigger that gave the first sign that the canoe was tilting.

Strong current and intermittent deft poling from the Binandere took us quickly downstream. With Tabara still out of sight another canoe joined our quiet convoy. It took station on the left. The rainforest on the banks was darkening with evening, but low-angle sun still lit the eastern edge of the river, and it fell on a spectral figure kneeling just forward of the stern poler in the strange canoe. The spectre was in fact a boy of about seven painted in grey clay, and dressed in 
broad green leaves and white streamers of beaten fibres. He was, we were told, representing the spirit of John's uncle, the man who had first brought mission schooling to the area. John's uncle had since died, but the boy honoured his place in John's education. There could be no Binandere precedents on how to greet a returning doctor of philosophy. George Kandoro of Tabara, John's cousin, had choreographed a new village ceremony.

The canoes rounded the last bend and the polers thrust for the papo, the shelving bank of the Tabara canoe landing. The papo is still for the river people what the steamer jetty was to the white men in the tropics, and what the railway station was to Australian country towns. The papo is the point where the Tabara have met the outside world. Brides from other villages have stepped ashore on its grey sand, some surrounded by families displaying their strength, others as trembling captives. Men have arrived at the papo to offer feasting, fighting, trading, treachery, a new religion and a new government. Women have wept when young men left to work on plantations or enlist in the army or the police, and they have wept again on the papo for those who returned and those who did not. And now when village groups from downstream want to arrive in style, white leaf-pennants flying and canoes low in the water with pigs, taro and bananas, they battle upstream close to the far bank, pass the village, then turn and race into the papo with the current.

At the papo we were met by drummers, dancers and a chanted welcome that swelled and died. Headdresses and leaf streamers waved with the gusts of sound. Spearmen raced forward, retreated and charged again. All the time the spirit-boy stood quietly at John's side. He was both shy and assured. The welcome was a compressed re-enactment of many meetings with strangers: the shouting of 'Who are you?' the challenge, violence, a treaty, and an invitation to the men's house.

From the front platform of the house set aside for us we looked out on swept earth surrounded by some fourteen other houses, each with its own split-palm floor, vertical lath walls and shaggy sago-palm thatch roof. Each house sat on posts, some over two metres high. The only useful plant cultivated right against the houses was tobacco. Old men plucked leaves, cured them over the fire, and rolled themselves a cigar as they talked. Beyond the houses were betel and coconut palms, behind them rain forest and the curve of the river. The food gardens, extending over two kilometres, were across the river where they were protected from the foraging village pigs. Logs lying on the ground marked off ownership and gardens in different stages of production: newly cleared land with timber piled to dry for fuel, freshly planted taro, tangles of sweet potato vines spilling from earth mounds, mature gardens dense with maize, tapioca, peanuts, cabbage, pumpkin, beans and onions, and old gardens in which even the sugar cane and banana palms were disappearing in the secondary rain forest. 
The Binandere led us through their gardens with pride. The obvious productivity does more than demonstrate that the Binandere possess fertile land and it works well: the constant harvest confirms for the Binandere the essential correctness of the way they organise their material and spiritual worlds.

The Tabara grow no cash crops. For a time Australian field officers tried to compel the villagers to grow tree crops, but economic laws were stronger than those of the government. Any harvest had to be carried on men's backs and in canoes to meet boats that did not come and for buyers who did not care. The Tabara found it cheaper to pay fines and easier to labour in gaol.

In the evening some women lit a fire in front of our house. We sat in the dark on our platform looking at other fires, trails of smoke, and people moving in and out of the shadows. A house, a young Binandere man told us, is not complete without its fire. Did we, he asked, notice a lone rock in the river? He took great care to remind us of the particular rock where the river was fast and shallow. That rock, he said, was once a house. No one lit a fire in front of it. Believing it had been spurned, the house left and became the rock.

At daybreak each morning there was a rhythmic swishing as Binandere women swept the arapa, the open space between the houses. When we first looked out on the arapa each day it was still patterned with the crescent strokes of the bush brooms. During the day fat pigs, healthy chooks and skinny silent dogs left one lot of shade, crossed the arapa, and found other shade. In Tabara the vegetarians and omnivores do well, and the carnivores struggle.

To a westerner the arapa could look like a street; but that is absurd for there are no vehicles, and no roads connect the village to anywhere else. And the Binandere do not see a space equally free to all pedestrians. They think of each house as having a claim to the arapa immediately in front of it. The Binandere feel more secure in their own section of arapa. The protective spirits of ancestors, they think, are more able to guide and guard them close to their own houses. A person suspicious of another does not lightly enter the rival's arapa, and a man wishing to make a strong speech stands before his own house.

We cooked some of our own food, but much of it came in leaf-covered bowls full of steaming taro, yam and banana. At the end of one meal I was asked if I wanted anything else. I said I wouldn't mind a small sugar banana. Someone, I thought, would just throw me one. In fact someone had to take a canoe across the river in the dark and walk to the gardens. About an hour after my request I was presented with an enormous branch of sprouting banana hands. While I tried to say that the bunch could be better used somewhere else, it was lashed to our platform. Next morning other branches were tied to our house. My suggestions that we could not possibly use so many bananas were met with cheerful indifference. 
Our house was thick with the scent of ripe bananas, and insects swarmed around the oozing fecundity. Had the kiawa slighted his hosts by asking for more at the end of a generous meal? Or was the display to demonstrate to other Binandere the capacity of our hosts to feed guests a reckless excess? Andrew preferred a sexual explanation. In asking a woman for a banana (a phallus) I had shown my ignorance of metaphor and biology. The thousand bananas celebrated and sustained a joke. That was why the Binandere sometimes slapped their thighs and laughed as they looked on the decaying reminders. Or perhaps there were reasons beyond kiawa speculation. One of the first things that a stranger learns is that he is not the centre of events; he is temporary; events matter in the way they change relationships between Binandere.

In 1930 F.E. Williams, the Papuan government anthropologist, wrote of the plays staged by the Orokaiva, a neighbouring Northern Province people. They were, he said, 'valuable as a source of pleasure and amusement, and as an art that is its own reward'. That was an unusual judgement for the time, one likely to bring guffaws of contempt from the white-suited men in Port Moresby's Papua Club. Williams wrote of the dance dramas, but the Binandere also put on impromptu farces. Young men prepare during the day, and in the evening present a play of capering, distorted faces, funny dress and knock-about jokes. Children become so convulsed with laughter they verge on hysteria.

One midday the young men said that they needed a whiteman for the play that they were putting on that night. No, we said, we admired the plays but we had no ability as actors. The whiteman, they assured us, had nothing to say, just sit there. He was a kiap, a government field officer; and the Binandere wanted me, I looked right. Sensing their own escape, Chris and Andrew were immediately converted to enthusiasm for the play.

I asked was it certain that the kiap was just a prop. Yes, yes. Just sitting. In that case I would be in it. The players conferred. It would be better if I would shout out in English to a Binandere question, 'I don't understand'. I agreed to the one line. The players again went into Binandere pre-production discussion. There was one more thing. The second time I was asked a question I had to shout, 'Have you got a licence?' 'Licence' in this context meant a letter of authority from a government officer. So I was dragged deeper into Binandere farce.

The incident forming the basis for the play was well known to the Binandere. In the early days of Australian control a group of Tabara men, conscripted to carry for a government patrol, were released from duty in the Goilala mountains and told to make their own way home. At Ioma they had to report to the kiap and collect rations for the final walk to Tabara. Only one of the Tabara carriers had been away to work on a plantation. He often entertained the villagers with stories of the outside world, and he demonstrated the strange ways of the 
whitemen by speaking their language and imitating their behaviour. When the tired Tabara carriers reached Ioma he was nominated to tell the kiap who they were and what they wanted. But in reality the only foreign words he had picked up on the plantation were isolated commands in English, swear words, and a few disconnected phrases in Police Motu, the lingua franca of the Papuan coast. To the admiration of his fellow Tabara and the complete confusion of the kiap he produced his jumbled vocabulary.
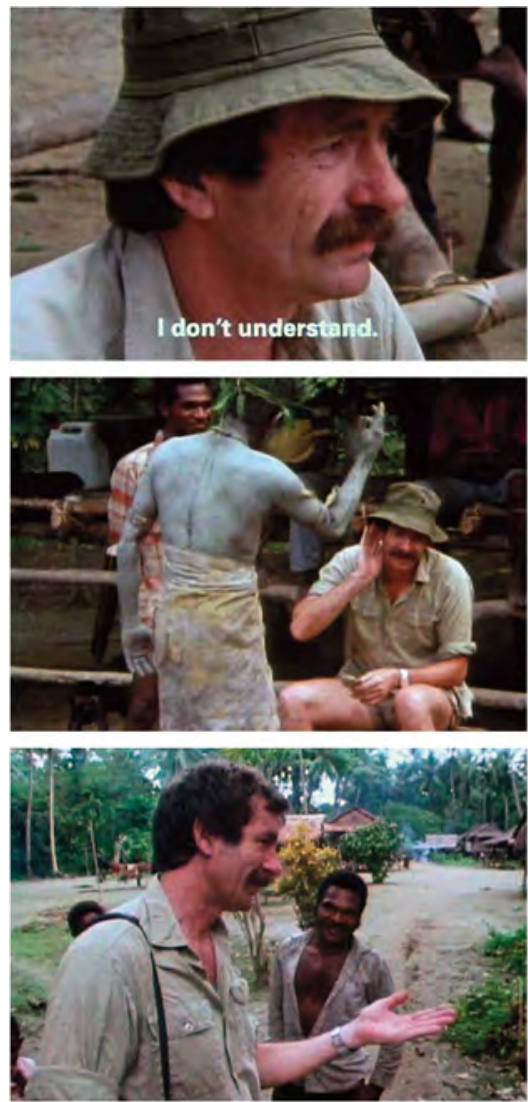
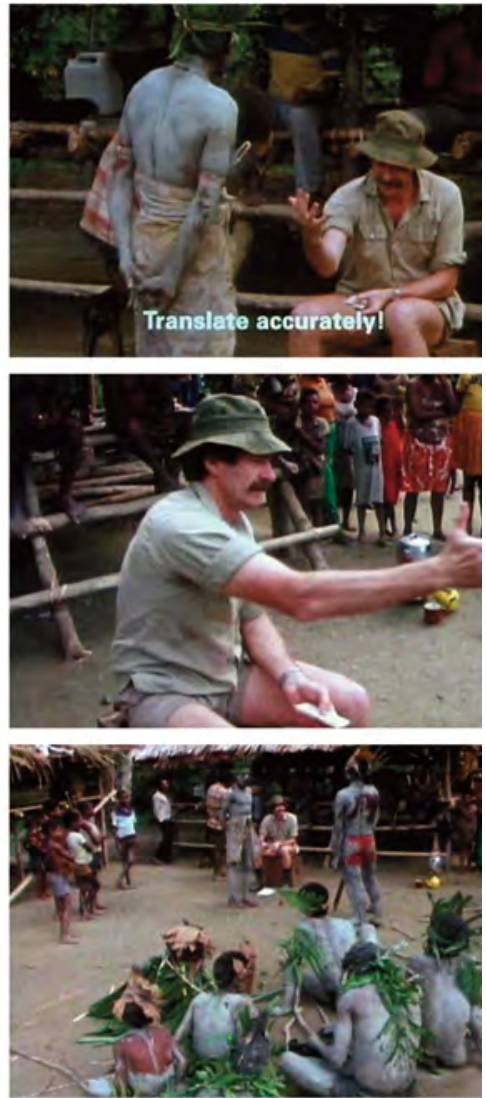

Figure 4: The kiap play sequence with Hank Nelson in Tabara village.

Source: Frames from Man Without Pigs, provided by Ronin Films.

In my role as kiap I sat on a patrol box in the arapa. A 'cookboy', obsequious to the point of shivering stupidity, kept bringing me cups of tea. The 'carriers' in strange clothes, faces painted in absurd contortions, stumbled into view. Their spokesman was pushed forward and he gave forth a volley of English and Motu. I shouted my first line: 'I do not understand!' The apparently terrified Binandere fell over backwards, the men in front knocking over those behind in a domino fashion. From then on it was ad libbing, random action and general chaos. 
The Binandere actors understood all that went on; the audience followed about eighty per cent; and with little warning of the plot and no comprehension of Binandere I understood about ten per cent. At what I thought an appropriate moment I came out with my second line and demanded a licence. Perhaps the timing was right, or perhaps I just added a further element of farce. With just two repeated lines from me the Binandere actors sustained over half an hour of sight gags, lewd asides, political satire and funny walks. The kiap was guyed, and so were the yokels and the pretentious of Tabara. The audience loved it.

Our planned entertainment for Tabara was the asisi wasiride, literally the moving spirit, the picture show. Nearly all the Tabara had seen pictures, but this was the first picture show in Tabara. To be able to throw pictures on to a sheet draped down the side of a house was logistically complex. We needed to have in the one place at the one time a two-stroke generator, fuel, a projector, and film. The compact Honda generator was also needed to recharge camera batteries so that Chris could keep shooting film. Under civil aviation regulations we could not take fuel on an aircraft that also carried passengers. Before we left Port Moresby Chris had arranged for the Papua New Guinea Office of Information staff - the travelling picture show men - to bring film, projector and fuel by boat along the coast, transfer to a smaller craft and come up the river.

On Thursday evening a man arrived from Manau on the coast. Through interpreters we learned that the Office of Information team had arrived at the coast, but had no outboard-powered dinghy to come up the river. After long discussions with other Tabara men John thought he could persuade them to take six outrigger canoes down to the mouth of the river, walk across to Manau, direct the coastal boat to stand off the Gira, load the canoes at dawn when the surf was down, and battle upstream through the next day. It would be a gruelling trip for the canoemen.

At about ten o'clock that night there was a cry, 'Dinghy gupeira, dinghy gupeira'. The dinghy was coming. Excited groups hurried to the papo. Through the heavy humid air I thought I could hear a distant motor. At times I imagined I heard the sound I knew in another place as the drone of a tractor working through the night, the farmer desperate to sow while moisture still darkened his Mallee paddock. The sound faded and we began walking back. High cloud covered the sky, but the near full moon gave just enough light to walk without torch or lantern. Only a patch of bamboo was absolutely black.

Again there was the cry of 'dinghy, dinghy'. We went back to the papo, and now the sound of an engine revving and dying was clear. Suddenly we saw a torch flashing, the outline of a boat and the white churn of the wake. Keeping in the deep water close to the far bank, the dinghy drew level with the papo. The villagers on the bank were calling out, and we picked up occasional comments 
translated into English. 'It's not our boat'. But the engine slowed and it turned towards the papo. 'They haven't got the pictures'. Then the torches on shore picked up the shine of metal film cans lying among the cargo. Like victorious warriors home from battle we carried stores, projector and film into the village. The women already had mugs of tea and bowls of food ready.

While the boatmen ate on our platform, Tabara men and women drummed, danced and sang. One woman left the dancers, warmed a drumhead on the fire, tested it with palm and finger taps, and returned to the dance.

John spoke quietly of the tenacity of the small boy and six men on the dinghy who kept driving their boat upstream with just a handheld torch to give them warning of rocks and timber. The Office of Information men said that they wanted to show the films immediately. They had a sea-going boat waiting near the mouth of the Gira and had to meet it the next day. No-one seemed surprised at the idea of starting a picture show close to midnight, but John pointed out that people in nearby villages were expecting to see the films and they would be unable to come to a sudden showing. The travelling picture show men agreed to leave their equipment with us.

The Office of Information men and the boat's crew were up before dawn, and left at first light. Early on that same Friday afternoon we discovered that they had taken all the petrol with them. We could neither show films nor recharge batteries. But, we were told, another dinghy was coming on Monday and it was carrying a forty-four gallon drum of bensin, petrol.

A saga of confusion over the petrol had begun. For me the confusion was increased because I was never sure of the source of the many conflicting messages, and I did not know whether others were hearing the same contradictions.

The second dinghy came the next day, Saturday. The boatmen had no fortyfour gallon drum, and, they said, only enough bensin to get back to Manau. At Manau they would store the dinghy until at some unknown time a coastal boat would drop off fuel. The nearest government station, Ioma, we were told, had no petrol. We wondered whether it was worth paying about $\$ 300$ for a charter aircraft to bring fuel to Dodoima. But a runner would take a day to reach Ioma and we were uncertain of the speed and accuracy of any response.

Someone remembered the mower at Dodoima. If there was an engine, there was bensin. But, no, for many months bent backs, sweat and swinging grass knives had cut all the cursed kiawa grass on the airstrip.

We were then told about driftwood bensin. A forty-four gallon drum had been washed away in a flood and found stranded in a creek by some villagers living upstream from Tabara. When the owner claimed the petrol, the villagers said he 
could have it after he paid them compensation. The owner had no money, and the finders kept the drum. The dinghy men left by canoe to see if they could buy the come-by-chance bensin. They were back the next day: the villagers did have a drum, but it was small and it only had enough petrol in it to cover the first joint of one finger. They left drum and bensin where it was.

As we sat on the house platform in desultory conversation, the boatmen speaking Binandere and us English, John in one of his comments that linked the two groups told us that there was some spare fuel on the dinghy. One of the boatmen, John and I went down to the papo and collected two plastic containers of oil, an auxiliary tank from the outboard and another four gallon drum of petrol. We could run the two-stroke generator to charge batteries and for several hours of films.

Had the boatmen given us the fuel that they needed to get back to Manau? Would they now have to drift and pole downstream, leave the dinghy on the river and walk across to Manau? Later when I gave one of the boatmen antibiotics for a tropical ulcer on his leg I tried to question him closely and casually. He said they still had enough bensin to get to Manau.

Placed in sequence and isolated from other events the story of the petrol has a step by step clarity. Even the contradictions are precise; the dinghy would come on Monday and it arrived on Saturday. But at the time I often heard half statements, searched for another person likely to be better informed, and asked for someone to interpret. And all the time other things were happening that were of immediate interest. The sago palm was cut, the sago pulverised, washed and carried in an old canoe hull into the village; the rehearsals for the ario, the dance drama, went on in the bush; visiting village groups arrived; prolonged discussions took place on the distribution of pig meat and other commodities; and there were emotional accusations and counter accusations of sorcerers being paid to impede the ceremonies.

Our pursuit of the bensin told us most of all that we were outsiders. The petrol actually existed, and our need for it could be explained easily. We could ask simple direct questions. But if we struggled to find out about petrol, then what chance did we have of learning about the non-material? We could observe and record, but it was doubtful whether we could find out what it all meant to those directing and taking part in events. As on other occasions when I have been fascinated by what I could see and bemused by village talk, I wondered about all those travellers and anthropologists who write crisp certainties with no admissions of bewilderment.

We showed the asisi wasiride over three nights. People walked for several hours or came by canoe, they ate with those linked to them by kin or some historical 
debt, and joined various groups on woven mats in the arapa. Soon small fires glowed at the front edge of several mats. Smoke drifted through the projector beam. Young men stood at the back where they could hear almost nothing of the sound-track above the hammering of the generator engine. Dogs and pigs scavenged cautiously for discarded food at the edge of the crowd of about 400 people. Late in the night children slept in positions of contented exhaustion.

Among the films we showed were a documentary by Chris on the Gogodala people of the Western Province of Papua New Guinea, his Pidgin language feature, 'Tukana', shot on Bougainville, and a documentary, 'Angels of War', made by Andrew Pike, Gavan Daws and me. 'Angels of War' includes scenes in which John interviews Orokaiva and Binandere ex-serviceman, so the Tabara saw one of the few films in which their own language is used.

During the films the Tabara talked among themselves, and directed occasional comments at the screen. They were quick to comment on the way other villagers carried out everyday tasks and behaved towards each other. In 'Tukana' the Tabara applauded quietly when the wicked suffered, and they were quick to express their consternation when young men and women scorned their parents. This was an immorality so extreme that the Tabara could not look at it dispassionately. To countenance such behaviour was to accept the destruction of Tabara. All in the audience knew that the towns with other values beckoned the Binandere young. In 'Angels of War' there is a scene where an Australian kicks a surrendered Japanese soldier. Australian audiences are embarrassed by the incident; the Binandere approved of Australian violence.

When people gathered in the village in the evening the sounds most likely to rise above the general noise were the cries of greeting and bursts of laughter. But as the egalitarian and competitive Binandere prepared to celebrate John's doctorate there was tension about contributions in work and kind, who would be hosts, and who would be artists and entrepreneurs. The prominence of one man or clan was detrimental to others. All acts to advantage or disadvantage someone would eventually be repaid. When clan leaders discussed plans in the evening, or when the dance leader denounced the men who could not reproduce the movements of the hornbill, men shouted, and a disruptive brawl always seemed possible. John's immediate family were the book-keepers of intricate village balances. They met in frequent low-voiced conferences to calculate the debts paid and incurred. Some older clan leaders might have been offering aid which they hoped that John could not repay immediately. Then they would have the right to call on him to act for them in Port Moresby in that alien culture of cash, forms to be filled in, and government patronage. 


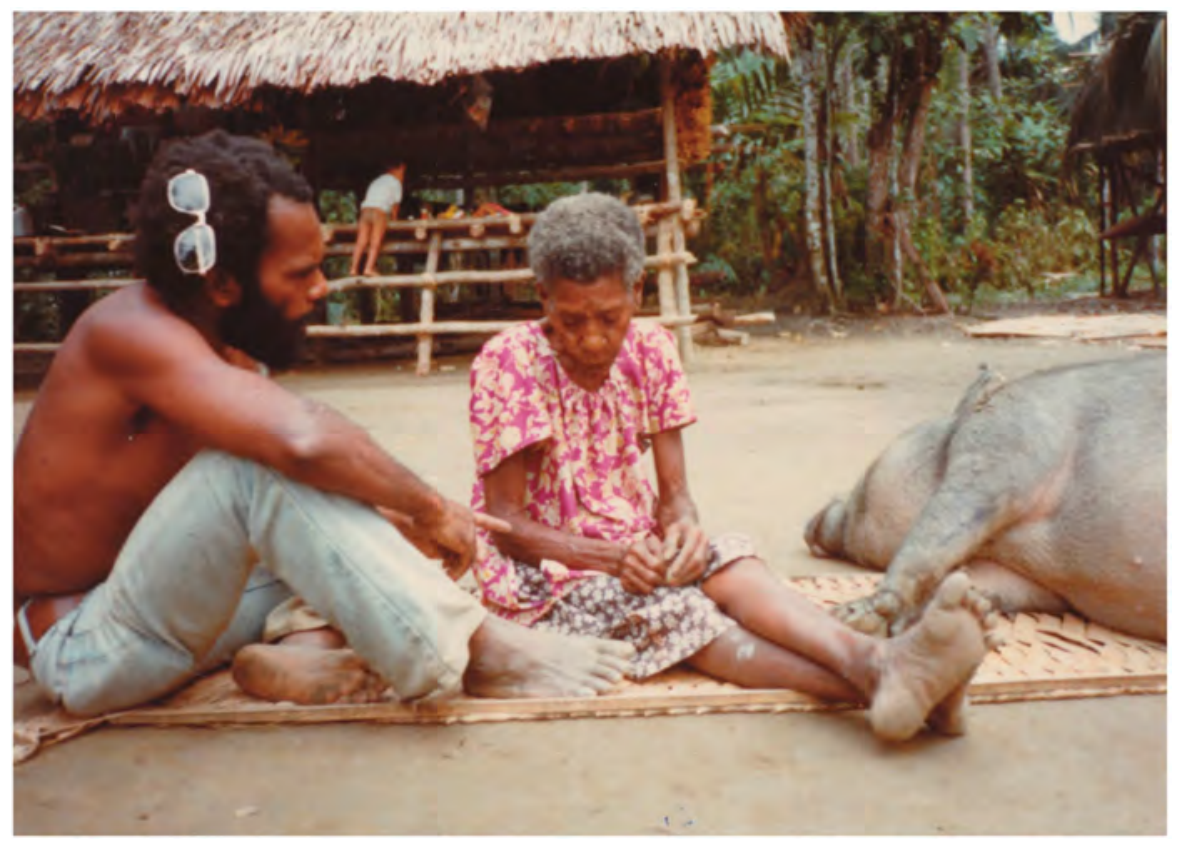

\section{Figure 5: Dr John Waiko with his mother in Tabara village at the time of filming Man Without Pigs.}

Source: Image provided by Ronin Films.

Before 9 o' clock on the morning of the first of two days of festivity people began collecting at a clearing about the size of a small cricket ground. It was like show day in a country town. Families carrying net-bags of food and green coconuts took up positions against the boundary vine. There was much shaking of hands as groups met, and constant chopping. Nearly all men and many women carried bush knives or tomahawks. They cut leaves to sit on and to drape on heads and shoulders. By midday some had cut poles and vines and built shade houses; and the bush that usually pressed against the clearing was hacked into retreat.

The young men, the farceurs, acted out a story familiar to the Binandere about a crying baby. Their appearance in bulbous masks and bodies covered in black and grey clay was more elaborate than in the impromptu evening capers. Women danced in pairs. They were without drums, but kept the beat with their feet and pounded the ground with the flattened ends of ginger stalks.

The main troupe of ario dancers entered the arena, and pairs of men and women came in from four different points. The dancing ground was a swirling mass of colour. Red earth dye mixed with the beaten bark of the simani and the intensely bright yellow of the scraped root of the nonda were everywhere shimmering and flouncing in layers of fibre draped from shoulders to ankles. All the men wore 
full headdresses with small feathers at the front through to the bird of paradise plumes at the back. White shell and dog-tooth ornaments were hung on chests and held in the mouth. Red-brown tapa cloth hung from waist bands. All men carried hand drums. Palm frond screens were shifted from the centre of the arena to reveal five-metre high carved poles supporting a stepped ramp leading to a platform above the height of the headdresses. A man and then a woman danced on the platform and displayed the yavetu, the bone of the dance, the motif, a baby-sized wooden figure carved secretly by Reginald Oveva, an artist from a neighbouring village. Bodies glistened with sweat. An old man dropped out, short of wind, he said. Women arrived with metal boilers of water and handed enamel mugs to the dancers. Old women sang a lament for those who had once danced in splendour but were now dead. Other women danced at the side of sons new to the ario. A dome, representing a cave, suddenly raced across the arena. There were people crouched inside giving the dome an eerie mobility. It was a dramatic coup. The hornbill dance, the sago dance and the wallaby dance were completed, and the Binandere had acted out legends defining where they came from and who they were. We left the dancing ground with its trampled grass, slashed branches already wilting, and litter of peel and husks. Back in the village we sat on the house platforms, ate and talked.

The next day the pigs to be killed were paraded shoulder high around the arapa. Still with front and rear legs tied to poles, the pigs were lined up along the dapamo, a tree trunk fixed horizontally about half a metre above the ground. John, dressed in The Australian National University doctoral robes, emerged from a house. People expressed quiet admiration for the blue-and-black gown. Perhaps they guessed that this was the dress of declamation rather than dance. Escorted by men in headdresses and tapa cloth, John led a procession around the arapa. Suddenly there were shouts in the crowd, a thud as a round-house right connected, and a club arced through the air. Someone blew a whistle, men and women rushed forward, and the hotheads were pushed apart. The Binandere share the paradox of other cultures: warriors are heroes and the peace-makers are blessed. At the height of the melee John said calmly, 'Think of this in the School of Music', the scene of his Canberra graduation. He then spoke to restrain his wildest supporters.

The flare of violence died quickly. The young men of Tabara had clashed with those from another village. Someone had stood up, the young men at the back had shouted for them to sit, there were comments, then insults and a fight. In another country the beer would have been blamed; but in Tabara there was no beer, no trade store and almost no exchanges involving cash. The fight was another incident in a long-lasting rivalry between the two villages. 

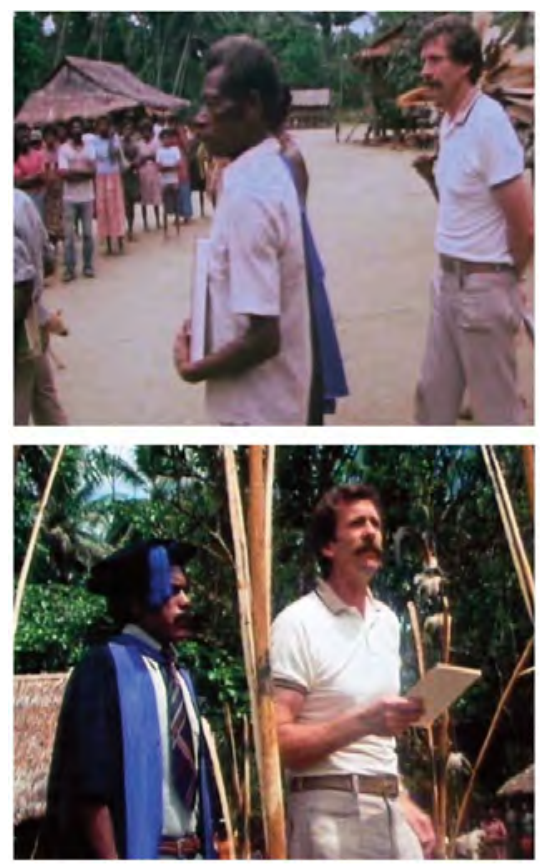
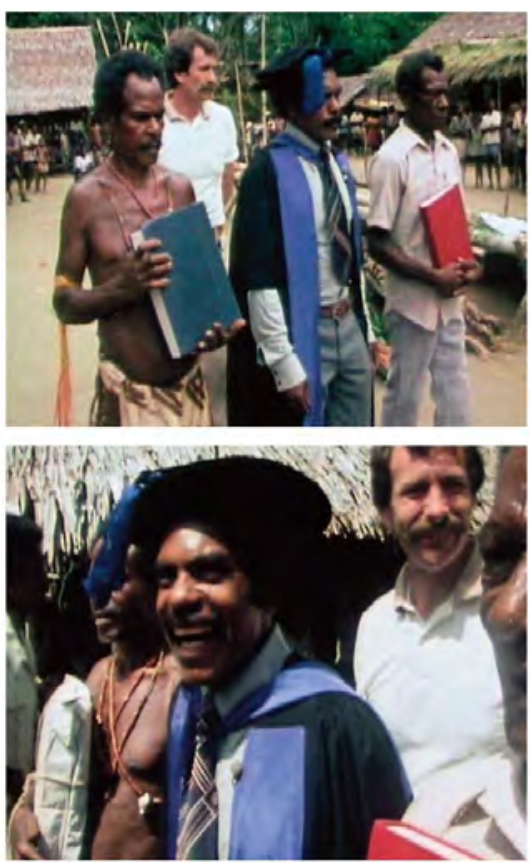

\section{Figure 6: The graduation ceremony in Tabara.}

Source: Frames from Man Without Pigs, provided by Ronin Films.

The procession moved on. John climbed a low platform especially built in the arapa. He addressed the people who remained close to their houses and shade. Nicodemus Kove, one of John's first teachers, spoke, and I tried to say what John had achieved in a foreign education system. I began, 'Ladies and gentlemen of Tabara edo nasi berari de. Ositeraria butu da ainda ...' I had written a paragraph and John had translated it for me to read. I continued in English and John turned the talk. Women put shade leaves and cooling water over pigs they had just fed, pigs that were known by name and were accustomed to lie close to the family mat in the evening. Other Binandere men spoke, then John walked the dapamo log to nominate those to receive pigs.

In the evening the young people began their 'disco'. A string band played all night. The lead singer, a young boy, knelt to project his voice into the microphone of the one guitar hooked to a battery-operated speaker in a radio. Most of the songs were in Binandere, adaptations of those played by the string bands of the Papua New Guinea towns. On the first day of celebrations the old arts of Tabara had been displayed on the dance ground; on the second day John in his doctoral robes had inserted a glimpse of another culture into the village; and the night of the second day belonged to the gita, the instrument that was changing church, funeral and dance music on the Gira. 
We left at dawn the next day and walked through flood waters to Dodoima. Our weather was clear, but storms in the ranges had sent a mass of swirling mud-coloured water down the river. We no longer had to worry about the log bridges; they had disappeared, and we swam in warm, opaque water. Our guide, Dudley, was a tall young Binandere of about fourteen. His English was the most fluent of those who were educated in the area and stayed there. At school he had been consistently around the top of his grade, but when the final primary school exam was held he was fourth, and only three Gira pupils were given places in the high school at Popondetta. John, in one of the services he could provide for his people, was trying to find a school that would take Dudley. At one creek Dudley made real what I had presumed was old masta folklore. He waded into the water, took a deep breath, held a bag of our gear at arm's length over his head, and kept walking. He had calculated correctly. The water rose to his wrists only, and he made the crossing in one breath.

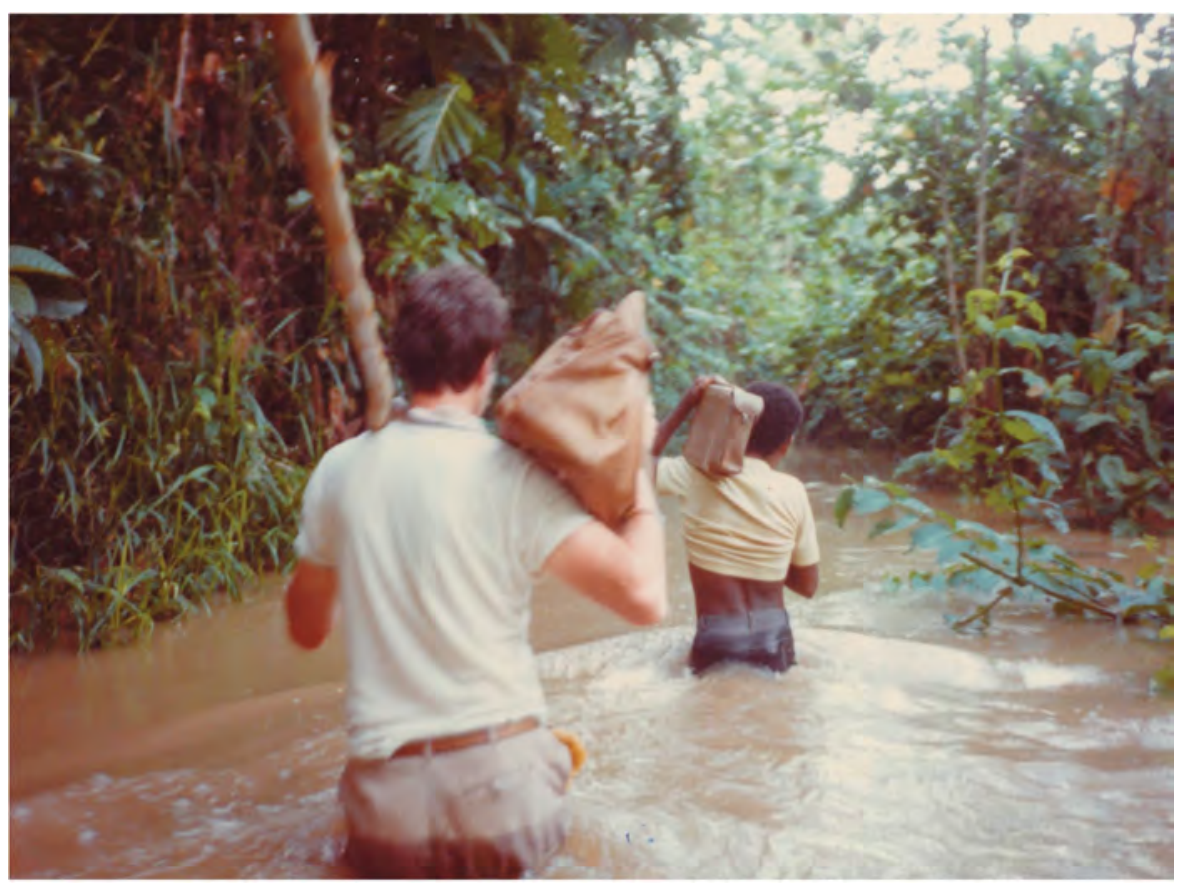

Figure 7: Hank Nelson in a flash flood on the Gira River, Oro Province.

Source: Image provided by Ronin Films.

As the water on flat parts of the track rose above waist level we wondered what was happening to the carriers who were following. The film, in taped cans, would survive immersion, but the sound tapes had little protection. We joked about reviving the silent documentary, the film in which you learnt to appreciate Binandere music by looking at it. But as we rested on a rise at Peio village, John 
and the carriers came yodelling and splashing through the flood. When the Gira rose they had cut timber, made rafts and floated the cargo. All the tapes were dry. We missed our charter flight. It roared overhead as we waded beneath a thick forest canopy. We could neither wave nor hurry.

By the time we reached Dodoima the Gira was almost contained within its banks, but its surface was still riled and heaving, it roared like surf, and mudstained foam hung on snags. The fall of the river was sharper here, and stones rolled in the stream. There were no more Binandere villages higher up the Gira. As we stood on the flood-washed bank looking at the river a man on a black motor tube swept into view. He went with such speed, the tube seemed to be skipping across the surface. Far out in the stream, he could not join a shouted exchange. He waved a relaxed arm and was gone. We could not ask whether he had long planned this day, how and why he got his tube to the Gira, did he have business down-stream, or was he a great opportunist. For us he was the man who took the flood, became the fastest man on the Gira, and for an instant gave us a share in his exhilaration. At the airstrip I wrote a note in case the pilot came back. It said we were in Usi village, just ten minutes' walk downstream. For a moment I thought about carving DIG into a soft-trunked tree, but decided that the Australian pilot might not have been instructed in the same repetitive explorer history as my generation. And nothing could have been more alien to Burke and Wills than the Gira and the rain forests where men became hornbills and danced in swirls of colour. I cut a stick and used it to pin the note to the split palm shed housing the no-bensin Scott Bonnar.

The charter picked us up two days later.

\section{NOTES}

Dr John Waiko obtained his Ph.D. in the Department of Pacific and Southeast Asian History at The Australian National University. As one of his supervisors I was invited to attend a celebration in his home village. I am grateful to John and the people of Tabara for their courtesy and generosity. Andrew Pike and Chris Owen were initiated as friends of John and as film makers. In various writings John has recorded much of the history of the Binandere people. I am grateful to John, Andrew and Chris for reading a draft of this article. 
This text taken from The Boy from Boort: Remembering Hank Nelson, Edited by Bill Gammage, Brij V. Lal, Gavan Daws, published 2014 by ANU Press, The Australian National University, Canberra, Australia. 